\title{
Tutankhamun Exhibition at the British Museum in 1972: A historical perspective
}

\author{
Asaad A. Zaki ${ }^{1}$
}

\begin{abstract}
The fiftieth anniversary of the discovery of Tutankhamun's tomb by Carter and Carnarvon was celebrated at the British Museum in 1972 by an exhibition "the Treasures of Tutankhamun". Fifty items from Tutankhamun's collection were selected to be displayed on this occasion in London; seventeen pieces were being displayed outside Egypt for the first time. The exhibition had a humanitarian purpose as it helped in the heritage conservation in Egypt; its proceeds were devoted to the UNESCO fund project for moving the temples of Philae to a higher ground. Special Agreements were signed between the British and the Egyptians regarding the exhibition items and its security.
\end{abstract}

Keywords: Tutankhamun's Exhibition 1972 - the British Museum - Museum history - Tutankhamun's tomb

To cite this article: Zaki, A.A. (2017). Tutankhamun Exhibition at the British Museum in 1972: A historical perspective. Journal of Tourism Theory and Research, 3(2), 79-88. DOI: 10.24288/jttr.312180

\footnotetext{
${ }^{1}$ Lecturer (Ph.D) at Department of Tourism Guidance - Faculty of Tourism and Hotels - University of Sadat City - Egypt. asaadzaky@fth.usc.edu.eg
} 


\section{Introduction}

The fiftieth anniversary of the discovery of Tutankhamun's tomb at Luxor by Howard Carter and Lord Carnarvon was commemorated in London by an Exhibition "the Treasures of Tutankhamun" at the British Museum in 1972. This exhibition was considered one of the most comprehensive and valuable displays of Tutankhamun objects ever to leave Egypt (Gift of relic to Britain, 22 March 1972). The exhibits were fifty items from the collection of Tutankhamun, flown to London for a six-month display as it was firstly agreed. It was the largest exhibit from this collection, seventeen pieces of them were being displayed outside Egypt for the first time (Edwards, April 1972), although smaller exhibits were shown in Tokyo in 1965 and in Paris in 1967 (Tutankhamun collection, 25 January 1972).

This article focuses on the importance of this exhibition, the inter-government negotiations regarding the Egyptian Government approval of displaying those items at the British Museum, the security measures, the exhibition publicity, its unveiling and its visitors' intensity. The article depends on the original documents related to the exhibition which are archived at the National Archives of the United Kingdom in London in addition to the newspapers as well.

\section{Tutankhamun Exhibition at the British Museum}

The Exhibition was not only organized for enjoyment, but also for a further purpose; the financial profits would be devoted to the United Nations Educational, Scientific and Cultural Organization fund project for moving the temples of Philae to a higher ground so that they would not be drowned, but would be preserved for the future generations (Tutankhamun Exhibition, 30 March 1972).

Tutankhamun, the ruler of Egypt was buried with his treasures for nearly 3.500 years. On 26 November 1922, fifty years before the exhibition, Howard Carter opened the entrance to the tomb and looked in, Lord Carnarvon asked Carter: "Can you see anything?" Carter answered: "Yes, wonderful things". Fifty items of these "wonderful things" were displayed in the exhibition at the British Museum in 1972 (James, 2000 - Tutankhamun, 29 March 1972).
To have the right of displaying those items at the British Museum in London, an agreement should be signed between the two concerned Governments; the British and the Egyptian, and another agreement between the Cairo Museum and the British Museum.

The British Government officials and the trustees of the British Museum prepared drafts of the InterGovernment and Inter-Museum agreements and sent them to the Egyptian Ministry of Culture on 2 February 1970 to be revised by the Egyptian legal authorities. There were two copies of the agreements of equal force; one in Arabic with the Government of the United Arab Republic and the Cairo Museum mentioned first and another copy in English with the British Government and the British Museum stated first. The British wanted to sign these agreements as soon as possible to facilitate the preparations for the exhibition, Lord Trevelyan, Chairman of the British Museum trustees said: "I trust that we can proceed to sign the agreements without delay" (Trevelyan, 2 February 1970).

The draft of the Inter-Government Agreement stated in its Article 3 that the Government of the United Kingdom should indemnify the Egyptian Government in respect of any loss or damage to the objects which would be exhibited at the British Museum by any cause whatsoever. The British treasury Department wanted to amend the terms of Article 3 of the proposed InterGovernment Agreement to exclude war risks and dangers arising from the situation which existed during that time between the United Arab Republic and Israel (Walkerm, 20 February 1970).

The British Department of Education and Science officials believed that the Egyptians would not accept the exclusion of war risks arising from the Arab-Israeli dispute which would mean that the Egyptians would get no compensation if the aircraft carrying the objects got too closely mixed up on an Israeli air raid (Walkerm, 27 February 1970). They were anxious that the negotiations with the Egyptians might be broken down at that stage after several months of talks with the Egyptian authorities (Walkerm, 12 March 1970). The Egyptian President Gamal Abd El Nasser refused for a time to let the British borrow these treasures. Eiddon Stephen Edwards, the head of the Department of Egyptian Antiquities at the British Museum, tried for years to persuade the Egyptians to let treasures of 
Tutankhamun be exhibited in London (Gaskell, 29 January 1972). There were British fears that if the proposed exhibition had to be canceled at this stage, the Egyptians would have the right to complain because several months of negotiations were wasted during which other arrangements for exhibition could have been made elsewhere. This cancellation of the exhibit could be interpreted as a political act (Gray, 19 March 1970).

Lord Trevelyan, Chairman of the British Museum trustees met Tharwat Okasha, the Egyptian Minister of Culture and Gamal Mukhtar, Head of the Egyptian Antiquities Service and the Under-Secretary of the Egyptian Minister of Culture in Egypt in March 1970 to negotiate about the war risks indemnity. Trevelyan told them that he hoped the British Treasury would agree to include the war risks in the indemnity and in case of their refuse, a separate insurance should be arranged against war risks which would be paid from the receipts of the exhibition. The Egyptian officials showed flexibility in the negotiation and raised no objection (Trevelyan, 24 March 1970).

The British Government indemnified the Egyptian Government of $£ 9.060 .000$ regarding any loss or damage to the fifty stated items in the annex to the Inter-Government Agreement, except any damage or loss occurred by the Egyptian Government officials from the time of the removal of the items from the Cairo Museum to their arrival at the same museum at the end of the exhibition. This indemnity extended to cover any loss or damage resulting from any procedure preventing the treasures to be returned to Egypt at the end of the exhibition. The indemnity excluded any loss or damage caused by any war or hostilities or warlike operations during transferring the objects between the Cairo Museum and the British Museum before and after the exhibition. In the case of the war risk or warlike actions, a separate insurance was arranged by the British Government of $£ 9.060 .000$, and was paid from the exhibition proceeds. This agreement was signed on 28 July 1971 (Inter-Government Agreement, 28 July 1971).

The Egyptian Government provided the displayed items only for that exhibition. It was the responsibility of the Government of the United Kingdom to protect them against any form of confiscation, takeover, or damage whether by another government or by an individual. According to the agreement, the British Government should take required measures for the physical security of the items from the time of their arrival in the United Kingdom until their departure (Inter-Government Agreement, 28 July 1971).

The exhibits had a sovereign immunity defended by the English law, so when a British man told DouglasHome, the Secretary of state on 29 March 1972 at the time of opening the Tutankhamun Exhibition that his grandfather died during the Second World War leaving possessions in Egypt; those assets were confiscated by the Egyptians and he, as inheritor, tried to get the assets back without result and asked the British authorities to get his right from the exhibition proceeds before they leave Britain (Littlejohn, 29 March 1972). The Commonwealth and Foreign Office refused his request clarifying that nobody had the right to have a claim against the exhibition proceeds as they would be paid into the UNESCO Fund for preserving the temples at Philae and not to the Egyptian Government and the exhibits themselves had a sovereign immunity as well (Holding, 7 April 1972).

The Inter-Government Agreement contained a list of the fifty items to be displayed at the British Museum in addition to the valuation of each item individually for the purposes of indemnity and insurance. Those items were selected by the directors of the Cairo Museum and the British Museum (Inter-Museum Agreement), the list of the items should not be changed or modified except with the permission of the British and Cairo museums' officials (Inter-Government Agreement, 28 July 1971).

The Egyptian Government did not bear any cost and did not have any financial responsibilities of any kind regarding the exhibition (Inter-Government Agreement, 28 July 1971). The exhibition was jointly sponsored by the British Museum and the Times newspapers (Wolfers, 25 March 1972) which were responsible for the finance and the administration of the exhibition (Inter-Museum Agreement). The Times newspapers had previous experience connecting with Tutankhamun's tomb; the news and the photographic arrangements of the tomb discovery in 1922 throughout the world was handled by The Times newspapers, this fact, together with the $150^{\text {th }}$ anniversary of the Sunday Times newspapers, encouraged the Times newspapers to sponsor the 
exhibition with the British Museum (Tutankhamun Exhibition, 30 March 1972).

Any dispute regarding the Inter-Government Agreement should be solved by direct discussions between the British and the Egyptians. If the direct negotiations did not solve the argument, a committee of arbitration should be formed of three members; each government should contribute with one member within a period of two months from the beginning of the formal dispute. The two nominated arbitrators should select, within a month of their nomination, the third member who should not be a national of either Government to be a chairman of the Committee. If the mentioned time of the nomination of the members was not respected, the President of the International Court of Justice should make the nomination. The decision of this committee should be final and obligatory (InterGovernment Agreement, 28 July 1971).

Following the Inter-Government Agreement, a separate agreement was signed between the directors of the Cairo Museum and the British Museum regarding Tutankhamun's Exhibition (Inter-Museum Agreement).

There was a main working party for planning, building and publicizing of the exhibition. Philip Taverner was the chairman; the other members were $\mathrm{E}$. S. Edwards, Keeper of the Egyptian Antiquities Department at the British Museum, Margaret Hall, Exhibition Officer at the British Museum who was responsible for design, Michael Brown, Financial Director at Times Newspapers Limited, and Guy Pearse as a secretary (Treasures of Tutankhamun) ${ }^{\star}$.

The exhibition was advertised in wide spread newspapers such as the Guardian, the Observer, the Times, the Daily Mail and other newspapers to clarify its significance, opening times and admission fees. The officials of the British Museum were keen to popularize the exhibition not only in Britain but also in Egypt; they invited the Egyptian Journalist Kamal ElMalakh who was an archaeologist to visit the exhibition to keep the Egyptian press informed of the exhibition news. They offered a grant of $£ 150$ for him from the exhibition funds (Edwards, 23 June 1972). The Foreign and Commonwealth Office invited other

- The Metropolitan Police Office was represented by Chief Superintendent P. Marshall as liaison officer to establish a proper Copyright (C) 2015 by JTTR four influential and reasonable Egyptian journalists to cover the exhibition news. They were carefully chosen as they represented the most widespread journals in Egypt during that time. This journalists delegate included Ibrahim Amer, Editor of Al Musawwar, Yusuf Sabbagh, Senior Editor of Al Ahram, Muhsin Muhammad, Deputy Editor of Al Akhbar, and Muhammad Al Azzabi, Deputy Editor of Al Gumhuriya (Craig, 28 March 1972).

Packing experts from London had flown to Cairo to pack the selected pieces into specially made cases (Hopkirk, 29 January 1972). The pieces were wrapped by foam rubber and plastic sheeting packed in wooden boxes (Gaskell, January 29, 1972). The exhibits were transported from Egypt to London Airport by special planes (Mannings, 6 September 1971). Massive security precautions were taken to protect the precious pieces; they were brought from Egypt in a secret airlift by the Royal Air Force (RAF) and the British Overseas Airways Corporation (BOAC) to London in three flights to spread any risk; two were by the BOAC jets and the third which included the mask by the RAF. When the two BOAC airplanes arrived at the Heathrow Airport, about a hundred policemen surrounded the plane and the pieces were transferred to waiting vehicles. The third airplane of the RAF landed at Brize Norton airport in Oxfordshire (Hopkirk, January 29, 1972). The airlift was insured for $£ 10.000 .000$ through Lloyd's Bank of London (Gaskell, 29 January 1972).

The packing cases were opened and foam rubber blocks were removed in the Department of Egyptology at the British Museum (Hopkirk, 29 January 1972). The packing and unpacking of the cases were carried in the presence of representatives of the Cairo Museum and the British Museum (Inter-Museum Agreement).

The Daily Mail estimated the potential visitors' number to the exhibition as many as two million (As they'll see us, 29 March 1972). As it was expected that the exhibition would be visited by two million visitors, it had the protection of an augmented museum staff to guard the exhibits (Commissioner of Metropolitan Police, 17 November 1969). The items were displayed in a specially strengthened gallery equipped with electrical devices and alarm systems. It was planned that these exhibits would be under considerable

connection between the Police and the British Museum (Waldron, 17 November 1969). 
security while they were at the museum (Mannings, 6 September 1971). The former Scotland Yard Murder Squad Chief, Jack Munings, was in charge of the operation and promised that his guards would be watching the pieces "every second of every 24 hours" (Lee-Potter and Lay, 29 March 1972).

Because of the vital role which was played by the policemen during the exhibition period, the Director and Principal Librarian of the British Museum John Wolfenden thanked the Superintendent C. Jackman, Albany Street Police Station. The Museum Director appreciated the helpfulness and cheerfulness of the officers as there were some occasional problems with members of the public because of the pressure of the queue outside the exhibition (Wolfenden, 17 January 1973).

The pieces were displayed in seven darkened rooms (Hopkirk, 3 April 1972); the first was equipped to prepare the visitors for the following rooms, it had photographs enlargements of the excavation in progress and the excavators in the field to tell the story of the tomb discovery. The next room contained the life-sized statue of the King, of blackened wood dressed in sheet gold represented in standing position carrying a gilded mace and a staff, it was one of the two statues standing in front of the door of the burial chamber. The following room contained a vase in the form of a standing lion, in an adjacent show case one of the four alabaster stoppers from the canopic chest and one of the four golden coffins that lay inside the chest and contained the mummified viscera of the dead King. Another room had the bed with sides in the form of slim and stilt-legged cows, which was one of the first wonderful things that stroke the eyes of Howard Carter on the discovery day in 1922 . There were also a series of elaborately inscribed chests and cabinets such as a child's chair which was inlaid with ivory, a small statue of the king chased in solid gold shows the king wearing the lion-cloth and the Khebresh (war) crown, a small shrine ornamented with gold panels depicting scenes in the daily life of the King, and other miniature pieces in addition to the most interesting piece in the exhibition which was Tutankhamun mask (Power, majesty and detail, 29 March 1972).

The Exhibition was unveiled on Wednesday, 29 March 1972 (Mannings, 6 September 1971). There were notable efforts to make the exhibition unveiling to be successful; the Foreign and Commonwealth Office officials considered this exhibition of considerable importance in the history of the AngloEgyptian relations and the history of the British Museum itself. They were keen to invite considerable persons during its unveiling (Holding, 29 April 1971).

Queen Elizabeth II opened the exhibition at the British Museum on 29 March 1972. The Queen was met by Mayor of Camden, Councilor A. E. Skinner, with B. H. Wilson, Town Clerk, Lord Trevelyan, Chairman of the British Museum Trustees, John Wolfenden, Director of the Museum, Lord Thomson of Fleet, Chairman of Thomson Organization, C. D. Hamilton, Chairman and Editor-in-Chief, The Times Newspapers Ltd, Mohamed Abdel Qadir Hatem, the Egyptian Deputy Prime Minister and Minister of Culture and Information, and Kamal Rifaat, Ambassador of the Arab Republic of Egypt in London. Lady Evelyn Beauchamp, the daughter of Lord Carnarvon, aged 70 years at that time, attended the formal opening of the exhibition. She was the last survivor of the persons who witnessed the opening of Tutankhamun's tomb on 26 November 1922. She was met by the Queen and was very delighted "utterly thrilled" by the way of displaying the pieces: "they look so much more beautiful here than they did down in the tomb", she said (Hopkirk, 29 March 1972).

In his speech in front of the Queen on the opening day of the exhibition, Lord Trevelyan said that they were unveiling an exhibition without parallel in the country. The Queen was delighted to be able to attend the inauguration of Tutankhamun Exhibition and said that she visited many buildings and places but none of them contained objects of such interest and beauty. The Queen thanked the Egyptian people for allowing these priceless pieces to be exhibited in London and valued the presence of senior Egyptian officials which symbolized the links between the two countries. Abdul Qadir Hatem who visited Britain for five days for the opening of the Tutankhamun exhibition was the guest of the British Government during his visit in London where he had a meeting with Alec Douglas-Home, the British Foreign and Commonwealth Secretary (Wolfers, 25 March 1972).

The Queen spent 40 minutes at the British Museum, the exhibits were explained to the Queen by E. S. Edwards, Keeper of Egyptian Antiquities who had 
chosen these items with the Egyptian officials to be exhibited at the British Museum, and by Gamal Mukhtar, the Egyptian Undersecretary for Antiquities (Hopkirk, 30 March 1972).

The British Minister responsible for the arts, Lord Eccles, expressed his gratitude to the Egyptians for sending such treasures and said: "an exhibition the like of which no other country in the world could send us". Abdul Qadir Hatem, Deputy Prime Minister of Egypt said: "the exhibition of the treasures of King Tutankhamun is a very happy mean of strengthening the cultural relations between our two countries". He hoped that the contact with the culture of the Pharaohs would strengthen the friendly relations between Egypt and Britain (Hopkirk, 29 March 1972).

The exhibition admission charge was $50 \mathrm{p}$ (Gaskell, 29 January 1972) while the Children under 12 years accompanied by adults and students paid $25 \mathrm{p}$. A restaurant was built in the forecourt of the museum, it was planned to serve 600 visitors an hour (Tutankhamun Exhibition, 1 April, 1972). The exhibition was opened from Tuesday to Saturday from $10 \mathrm{am}$ to $9 \mathrm{pm}$, and on Sundays from $2 \mathrm{pm}$ to $6 \mathrm{pm}$. Last admissions were about an hour before the closing times (Catalogues for Tutankhamun, 10 April 1972). It was opened on Mondays from $3 \mathrm{pm}$ to $9 \mathrm{pm}$; it was closed to the public until $3 \mathrm{pm}$ on Mondays so that school parties could be taken round (Hopkirk, 3 April 1972).

A large number of the British were curious to have a look at the treasures of the young King. A queue was formed outside the British Museum more than 14 hours before its opening for public visitors on 30 March morning. A man at the head of the queue camped and was tucked in a sleeping bag overnight despite the cold because he heard of the eight-hour long queues when the exhibition was unveiled in Paris in 1967 (Overnight queue, 30 March 1972). The people at the back of the queue were sometimes warned that there was no chance of getting in (Burden, 3 April 1972). To avoid the crowd in the exhibits, the flow through the exhibition is being regulated. When one room emptied, an attendant allowed the next group to enter. People had not been discouraged by reports of eight-hour queues and of visitors who waited for hours and could not get in the exhibition (Hopkirk, 15 April 1972). The organizers were restricting the flow of visitors so that all could glaze the treasures comfortably. A count was to be taken each evening so that, if needed, people who were waiting in the queue outside the exhibition could be told that they might not be able to get in that day (Tutankhamun Exhibition, 1 April 1972).

Visiting Tutankhamun Exhibition was a firm favorite with the British public since Howard Carter discovered his tomb just fifty years before the exhibition at the British Museum (White, 30 December 1972). The visitors considered the exhibition of Tutankhamun in London a cheap flight to Cairo and much quicker than going to see these treasures at the Egyptian Museum (Daley, 24 May 1972).

A handicapped man envied the visitors who could see the exhibits of Tutankhamun at the British Museum. He complained that there was not sponsored effort to help the handicapped people to get in the exhibition too (Ball, 6 April 1972). There were many British residents who because of age or sickness could not stand for hours in the queue. Some of those people would be glad to pay a higher fee to let them get in without waiting outside the exhibition (Williams and Godlee, 6 April 1972).

4.400 people visited the exhibition of Tutankhamun on its first day for the public visitors on 30 March 1972 (4,400 see Tut, 1 April 1972), more than 30.000 people visited the exhibition during its first week (Tutankhamun treasures, 8 April 1972), and more than 62.000 visitors saw the treasures of Tutankhamun in its first two weeks (Hopkirk, 15 April 1972).

The Exhibition had an influence on British school students; it inspired a team of a British primary school in Somerset, in southwest England, to design a musical play based on the life of Tutankhamun. The cast comprised 105 children who spent most of the term on the project. The play started with the accession of Tutankhamun and covered events up to his death. Three parties from this school visited the exhibition (Waymark, 18 March 1972).

A catalog was designed by E. S. Edwards and was released for the exhibited items, its price was $75 \mathrm{p}$ and was bought from a caravan near the queues of waiting visitors so that they could obtain the information before they enter (Catalogues for Tutankhamun, 10 April 1972). 50.000 copies of this catalog were sold in the first month of the exhibition (Edwards, 2 May 
1972). The Keeper of Egyptian Antiquities at the British Museum sent copies to the Egyptian Ministry of Culture to be given to senior officials in Egypt (Goulding, 25 April 1972).

A souvenir poster for Tutankhamun was produced by the Times newspapers with a single image of the golden mask (27 inches by 39 inches). It was printed in four colours on heavy art paper. The poster was sold in the poster shops and at the British Museum for $90 \mathrm{p}$ (Tutankhamun poster, 20 April 1972). These colour posters were ran out of stock many times from the railings outside the British Museum (Walter, 2 April 1972).

Stamps were issued on 26 April 1972 to commemorate the fiftieth anniversary of the discovery of Tutankhamun's tomb and to be sold during the time of displaying Tutankhamun's treasures. The stamps were bought for $65 p$ each and another one for $3 p$ which showed a head of the golden statuette of the King found in the tomb and one of the pieces which were displayed in the exhibition (Multiple Display, 8 April 1972). Some of these commemorative stamps were presented to members of diplomatic corps in the United Kingdom (Holding, 1 May 1972).

The production of any replica or representation for any displayed item in the exhibition and any scientific or technical work on the items required a permission from the Cairo Museum (Inter-Museum Agreement). The sculptor Mick Mahoney created two models of the golden mask of Tutankhamun; one of them was limited edition of 200 inches gold and exactly half-size, retailing at between $£ 150$ and $£ 200$, and another different model in simulated gold at around $£ 34$ to $£ 45$ (Walter, 2 April 1972). The officials of the exhibition sponsors were surprised on the first day because all the available replicas of Tutankhamun's jewelry were sold such as pendants, bracelets and rings (Tutankhamun Exhibition, 1 April 1972). To help profits along, a special sales area was designed through which all visitors should pass on leaving, with eighteen girls selling the books, cards, mementos, posters, postcards, colour slides, wall charts, jewelry, stamps, and even the carrier bags (Walter, 2 April 1972).

\footnotetext{
- The Department of Education for Scotland asked about the possibility of transferring the exhibition to the Royal Scottish
} Copyright (C) 2015 by JTTR
To satisfy the demand for background material on the life and customs of the ancient Egyptians, especially those of Tutankhamun, the Sunday Times, the co-sponsor of the exhibition, published the land of Tutankhamun wall chart; it was considered an educational aid for teachers and students and was available for $95 \mathrm{p}$ (Tutankhamun wall chart, 3 April 1972). The proceeds from the photographs and publications which were specially prepared for the exhibition were treated as a part of the exhibition revenue for the fund of the UNESCO to preserve the temples at Philae (Inter-Museum Agreement).

According to the Inter-Government Agreement, the items should be displayed for six months at the British Museum, but due to the high demand to visit the exhibition, there were discussions in London about the possibility of extending the exhibition beyond the arranged six months. The Trustees of the British Museum held a meeting at the Museum on 13 May 1972 and asked for extending the exhibition (Edwards, 2 May 1972). The Egyptian officials of the Ministry of Culture asked the British to apply formally for Egyptian agreement without delay as early as possible, especially the Soviet Ambassador in Cairo asked for the Tutankhamun objects to go on from London to Moscow, but the Under-Secretary of the Egyptian Minister of Culture saw that it would be better for the items to come back to Cairo before going to Moscow (Goulding, 25 April 1972).

The organizers of the exhibition applied for an extension as they expected 1 million people to visit the exhibition. The attendance in the beginning of September 1972 was 800.000 (Barker, 13 July 1972). This application was formally sent to the office of Abdel Qadir Hatem on 12 July 1972 (telegraph to the British Embassy, 13 July 1972). They asked for the extension beyond the planned closing date of the $30^{\text {th }}$ of September to meet the great demand to visit the exhibition and to be extended to 31 December 1972, the provisions of the Inter-Government Agreement of 28 July 1971 would be applied to the extended period (Urwick, 12 July 1972).

The Egyptian Government agreed to the British request to extend the exhibition by three months on 11 September $1972^{\circ}$. The exhibition was as popular as

Museum at the end of the exhibition period at the British Museum. It was difficult for the Egyptian officials to agree as they were ISSN: 2548-7583 
ever and the both sides, the British and the Egyptians, believed that it should continue to attract more visitors until its end (Edwards, 1 September 1972 - Extended, 9 January 1972). The approval of the exhibition extension indicated to the Egyptian desire to strengthen and flourish the cultural relations between the two countries (Hatem, 7 September 1972).

The Exhibition was closed on the last of 1.602 .000 visitors on 31 December 1972, the proceeds were nearly $£ 600.000$ for the archaeological rescue work in Philae temples in Egypt after deducting the running and construction costs. The bulk of the money came from $£ 695.000$ admission fees, the sale of 46.000 catalogs, and the showing of a film on the exhibition which brought $£ 33.000$ (MacManus, 1 January 1973), and a further $£ 3.000$ were collected in a box at the Exhibition exit (Hopkirk, 3 May 1973).

After deducting all exhibition costs incurred in connection with it, the British Government arranged for the payment, in sterling, of the proceeds of the exhibition to the fund which was administered by the UNESCO for the preservation of the temples at Philae (Hopkirk, 30 March 1972). A handing-over ceremony for the sums of money resulting from the Exhibition was held in the Board Room of the Times newspapers in London on 2 May 1973 to present $£ 600.000$ to the UNESCO. The ceremony was attended by senior officials of the Egyptian and British Governments; Gamal Rifaat, the Egyptian Ambassador in London and Gamal Mukhtar, the Egyptian Under-Secretary of the Ministry of Culture were invited to attend this event. The cheque was presented from Lord Trevelyan, Chairman of the British Museum Trustees to René Maheu, Director General of the UNESCO. The London Exhibition proceeds were more than the Tutankhamun Exhibitions of Paris in 1967 which ran for seven months and netted $£ 197.343$ and the Exhibition of Tokyo in 1965 and yielded $£ 467.860$ (Hopkirk, 3 May 1973).

The exhibitions had many benefits; the British Museum trustees could understand some items in the Egyptology collection of the British Museum better. Although the exhibition had meant the longest-ever working hours, it improved attendance in other parts of the museum. Edward Schofield, assistant secretary of the British Museum indicated that the number of visitors in the other parts of the museum was 1.4 million in the first six month of the year 1972, with an increase of 200.000 visitors on the first half of the last year. Until that time, the museum visitors' number had been climbing at a rate of about 200.000 a year (Barker, 1 September 1972). The Egyptians would gain financial and prestigious advantages. Although some people in Egypt opposed the idea of external exhibitions based on the fear of decreasing the potential tourists number, the coverage in the newspapers about this exhibition caused an actual increase in the Egyptian tourist trade according to the Egyptian Tourist Information Centre in London (Raouf, 14 April 1972).

\section{Result and recommendations}

The exhibition supported many years of archaeological relations between Egypt and Britain. The exhibition proceeds went to a valuable cause, during that time, the UNESCO succeeded in raising the Abu Simbel Temples above the Nile water, and it did the same for Philae Temple with the exhibition proceeds.

The British authorities considered the Tutankhamun Exhibition provided to be a considerable success and proved to be an important landmark in Anglo-Egyptian relations. This success was achieved due to the co-operation the British received from the Egyptian Ministers and officials. The British officials wanted to reinforce the effect of the exhibition by presenting those Egyptian officials and other influential Egyptians with copies of the commemorative stamps and catalogs related to Tutankhamun (Holding, 20 April 1972).

This study recommends future research on the impact of this exhibition and other external antiquities exhibitions on the international relations in general and on the Anglo-Egyptian relations in particular. While the Egyptian Government approved a British application to host Tutankhamun Exhibition, it rejected

be more difficult to transfer the items to Edinburgh which would require a new agreement.

(Holding, 3 May 1972) \& (Holding, 12 October 1972). 
the American request to held such exhibition at American museums, it was a matter of policy and international relations.

\section{References}

“As they'll see us?”, (29 March 1972), Daily Mail, 6.

Ball, Kathleen, (6 April 1972). “Tutankhamun”, Daily Mail, 21.

Barker, Dennis, (1 September 1972). "Tutankhamun gets more time", The Guardian, 7.

Burden, Garth, "Tut fans work up a thirst”, (3 April 1972). Daily Mail, 3.

"Catalogues for Tutankhamun queues to read", (April 10, 1972). The Times, 15.

Craig, A. J. M., (28 March 1972). A note of Near East and North Africa Department at the Foreign and Commonwealth Office, Tutankhamun Exhibition London, FCO 39/1238, the National Archives of the United Kingdom, Surrey, UK.

Daley, Michael, (24 May 1972). "letters to the editor: cheap flight to Cairo", The Guardian, 12.

Edwards, I. E. S., (April 1972). "Some Reflections on the Tutankhamun Exhibition", The Magazine, Vol. 114, No. 829, 202.

Burlington

, (2 May 1972). A Letter to M. I. Goulding,

Head of Chancery, the British Embassy in Cairo, Tutankhamun Exhibition - London, FCO 39/1238, the National Archives of the United Kingdom, Surrey, UK.

(23 June 1972). A letter to Gamal Mukhtar, Egyptian Under-Secretary of Ministry of Culture on, Tutankhamun Exhibition - London, FCO 39/1239, the National Archives of the United Kingdom, Surrey, UK.

(1 September 1972). A letter to Gamal Mukhtar, Egyptian Under-Secretary of Ministry of Culture, Tutankhamun Exhibition - London, FCO 39/1239, the National Archives of the United Kingdom, Surrey, UK.

"Extended”, (9 January 1972). The Guardian, 1.

Gaskell, Jane, (29 January 1972). "Unveiled at lastTutankhamun", Daily Mail, 21.

"Gift of relic to Britain for Abu Simbel aid", (22 March 1972). The Times, 15.

Goulding M. I., (25 April 1972). A Letter to I. E. S. Edwards, Keeper of Egyptian Antiquities at the British Museum, Tutankhamun Exhibition - London, FCO 39/1238, the National Archives of the United Kingdom, Surrey, UK.

Gray, J. W. D., (19 March 1970). A Letter to M. A. Walker, Department of Education and Science, FCO 39/749, Tutankhamun Exhibition in London in 1972 - the National Archives of the United Kingdom, Surrey, UK.
Hatem, Abdel Qader, (7 September 1972). A letter to A. B. Urwick, the British Embassy in Cairo, Tutankhamun Exhibition - London, FCO 39/1239, the National Archives of the United Kingdom, Surrey, UK.

Holding, M. A., (7 April 1972). A Letter to Claims Department at the Foreign and Commonwealth Office, Tutankhamun Exhibition - London, FCO 39/1238, the National Archives of the United Kingdom, Surrey, UK.

(20 April 1972). A Letter to D. H. Beaumont, Stamp Division, Marketing Department Postal Headquarters, Tutankhamun Exhibition - London, FCO 39/1238, the National Archives of the United Kingdom, Surrey, UK.

, (29 April 1971). A note, Exhibition of antiquities (Tutankhamun) from United Arab Republic at British Museum, London, March-September 1972, FCO 13/455, the National Archives of the United Kingdom, Surrey, UK.

, (1 May 1972). A Letter to M. I. Goulding, Head of Chancery, the British Embassy in Cairo, Tutankhamun Exhibition - London, FCO 39/1238, the National Archives of the United Kingdom, Surrey, UK.

, (3 May 1972). A Letter to M. I. Goulding, Head of Chancery, the British Embassy in Cairo, Tutankhamun Exhibition - London, FCO 39/1238, the National Archives of the United Kingdom, Surrey, UK

(12 October 1972). A Letter to I. Gray, Department of Education for Scotland, Tutankhamun Exhibition - London, FCO 39/1240, the National Archives of the United Kingdom, Surrey, UK.

Hopkirk, Peter, (29 January 1972). Tutankhamun secret air cargo, The Times, 1.

(29 March 1972). "Queen sees Tutankhamun treasures today", The Times, 1.

(30 March 1972). "Queen impressed by Tutankhamun treasures", The Times, 1.

, (3 April 1972). "Egyptians queue to see the treasures", The Times, 2.

, (15 April 1972). "Tutankhamun visitors not deterred by queues", The Times, 4.

The Times, 4.

(3 May 1973). Exhibition netted $£ 600,000$,

Inter-Government Agreement, (28 July 1971). Agreement concerning the Tutankhamun Exhibition and Agreement between the British and Cairo Museums, FO 93/32/110, the National Archives of the United Kingdom, Surrey, UK.

Inter-Museum Agreement, (28 July 1971). Agreement concerning the Tutankhamun Exhibition and Agreement between the British and Cairo Museums, FO 93/32/110, the National Archives of the United Kingdom, Surrey, UK. 
James, T. G. H., (2000). Howard Carter: The Path to Tutankhamun, (Tauris Parke Paperbacks; London), 219.

Lee-Potter, Lynda \& Lay, Richard, (29 March 1972) "The boy king really was somebody", Daily Mail, 7.

Littlejohn, C. R., (29 March 1972). A letter to Alec DouglasHome, Secretary of State, Tutankhamun Exhibition London, FCO 39/1238, the National Archives of the United Kingdom, Surrey, UK.

MacManus, James, "Tut top of the pops”, (1 January 1973). The Guardian, 24.

Mannings, J., (6 September 1971). A Letter to John Waldron, Commissioner of Police of the Metropolis New Scotland Yard, MEPO 26/3, Metropolitan Police Office - the National Archives of the United Kingdom, Surrey, UK.

"Multiple Display Advertising Items", (April 8, 1972). Daily Mail, 20.

“Overnight queue for boy king”, (March 30, 1972). Daily Mail, 9.

Parker, Julia L., (27 March 1972). "Tutankhamun on stamps", The Times, 13.

"Power, majesty and detail in a memorable exhibition", (March 29, 1972). The Times, II.

Raouf, Samir, (14 April 1972). A Letter to M. A. Holding, Near East and North Africa Department at the Foreign and Commonwealth Office, Tutankhamun Exhibition London, FCO 39/1238, the National Archives of the United Kingdom, Surrey, UK.

Telegraph to the British Embassy in Cairo, (13 July 1972). Tutankhamun Exhibition - London, FCO 39/1239, the National Archives of the United Kingdom, Surrey, UK.

Trevelyan, H., (2 February 1970). A Letter to Gamal Mukhtar, the Egyptian Under Secretary of Antiquities, FCO 39/749, Tutankhamun Exhibition in London in 1972 - the National Archives of the United Kingdom, Surrey, UK.

(24 March 1970). Report of visit to Egypt in March 1970, FCO 39/749,

“Tutankhamun”, (29 March 1972). The Guardian, 10.

"Tutankhamun collection flown to London" (25 January 1972). The Times, 6

"Tutankhamun Exhibition at British Museum opened by the Queen", (30 March 1972) The Times, 3.

"Tutankhamun Exhibition seen by 4,400 people on the first day", (1 April 1972). The Times, 1.
“Tutankhamun poster", (20 April 1972). The Times, 3.

"Tutankhamun shown on new stamps", (22 March 1972). The Times, 18.

“Tutankhamun treasures seen by 30,000”, (8 April 1972). The Times, 14

“Tutankhamun wall chart”, (3 April 1972). The Times, 2.

Urwick, A. B., (12 July 1972). A Letter to Abdel Qader Hatem, Egyptian Deputy Prime Minister and Minister of Culture and Information, Tutankhamun Exhibition London, FCO 39/1239, the National Archives of the United Kingdom, Surrey, UK.

Waldron, John, the Commissioner of Metropolitan Police, (17 November 1969). MEPO 26/3, Metropolitan Police Office - the National Archives of the United Kingdom, Surrey, UK.

Walkerm, M. A., (20 February 1970)., A Letter to J. W. D. Gray, North African Department - Foreign \& Commonwealth Office, FCO 39/749, Tutankhamun Exhibition in London in 1972 - the National Archives of the United Kingdom, Surrey, UK.

(27 February 1970). A letter to Foreign \& Commonwealth Office, FCO 39/749, Tutankhamun Exhibition in London in 1972 - the National Archives of the United Kingdom, Surrey, UK.

(12 March 1970). A letter to J. W. D. Gray, North African Department - Foreign \& Commonwealth Office, FCO 39/749, Tutankhamun Exhibition in London in 1972 - the National Archives of the United Kingdom, Surrey, UK.

Walter, Richard, (2 April 1972). "Tutankhamun's treasure trail", The Observer, 12.

Waymark, Peter, (18 March 1972). "Boy-king put to music for children", The Times, 2.

White, Michael, (30 December 1972). "The art of diplomacy", The Guardian, 13.

Williams, Griffith \& Godlee, Nicholas, (6 April 1972). The Times, 13.

Wolfenden, John, (17 January 1973). A Letter to the Superintendent C. Jackman, Albany Street Police Station, MEPO 26/3, Metropolitan Police Office - the National Archives of the United Kingdom, Surrey, UK.

Wolfers, Michael, (25 March 1972). Cairo visitor for Tutankhamun show's opening, The Times, 6.

“4,400 see Tut”, (April 1, 1972). Daily Mail, 3. 